\title{
HEAD-NEGATING ENCLITICS IN KET
}

\author{
Edward J. Vajda \\ Western Washington University/ Max Planck Institute for Evolutionary Anthropology
}

\begin{abstract}
This paper investigates bound relational morphemes (RMs) in the Ket language isolate of Siberia. While certain RMs have traditionally been called case suffixes and others postpositions, not even those labeled dative or ablative display all of the properties identified by Plank (2002) as characteristic of canonical case markers. Many can attach to finite verbs as well as nouns or pronouns, imparting analogous meanings in either combination. Formal differences among RMs, such as the presence or absence of a pronominal connector, fail to coincide with any functional division between case-like markers with general meanings, postposition-like morphemes, and converbs used to subordinate finite verbs in complex sentences. A prosodic analysis reveals RMs to be clitics rather than affixes, casting doubt on their capacity to build true word forms. We argue that Ket relational enclitics comprise a unified morphosyntactic category that creates adjuncts by negating the head status of nominals or finite verb forms. These morphemes convert head-bearing form classes into non-heads rather than build discrete inflectional paradigms of lexemes belonging to a particular part of speech. This interpretation supports the view of Krjukova \& Grishina (2004) that Ket syntax is founded on a basic division between nominal, finite verb, and non-head (i.e., modifier). Forms with head-negating enclitics represent the set of morphologically marked non-heads.
\end{abstract}

\section{Introduction}

Considerable debate surrounds the question of whether Ket has a case system. Based on semantic parallels with the commonly known inflectional-suffixing languages of Eurasia, Werner (1997) identifies a dozen case suffixes, including a vocative. Vall \& Kanakin (1990:6869), citing the ability of certain of these markers to appear independently of any preceding noun or pronoun and the absence of case marking for grammatical arguments, conclude that Ket lacks a true system of case inflections. However, Vall \& Kanakin do not offer an alternate account of the functional status of the morphemes at issue that explains why they are also added to conjugated verb forms.

Ket uses a variety of postposed bound relational morphemes (henceforward "RMs") to transform nominals (pronouns and nouns) as well as conjugated verb forms into adjuncts. A subset of RMs has generally been regarded as a case system (Castrén 1858; Dul'zon 1968; Werner 1997; Vajda 2004), the remainder being assigned the status of postpositions (Sherer 1983; Werner 1997). This interpretation will be referred to as the traditional analysis, although no consensus has developed on how to distinguish Ket "case markers" from "postpositions". One problem is that the primary formal difference among these morphemes - the presence vs. absence of a pronominal possessive augment - fails to coincide with any functional distinction between case-like vs. non case-like semantics.

Formally, Ket RMs fall into two groups. Some attach directly to the noun, pronoun, or finite verb over which they have syntactic scope. These will be referred to as "simple" or "nonaugmented RMs" and include several morphemes traditionally regarded as case suffixes, including locative $k a(1,3)$, as well as some that Werner (1997) labels postpositions. The latter group contains the translative morpheme $\varepsilon s a \eta$, used for assigning predicate complements such meanings as 'in order to find, get, be, become' $(2,4)$.

(1) The locative morpheme used with a noun 
$\begin{array}{lll}s \varepsilon ́ s-\boldsymbol{k} \boldsymbol{a} & q a ́ d d \supset q & \text { aqtá-m } \\ \text { river-LOC } & \text { very } & \text { good-N.PRED }\end{array}$

It is very nice at the river.'

(2) The translative morpheme used to mark the complement of a morphologically intransitive verb

bū qój-esay dbúpluвo

he bear-TRANSL he.looked (in order to find)

'He was looking for a bear.'

In many instances, the relational morphemes in question - whether traditionally regarded as case suffixes or postpositions - may also attach to conjugated verb forms. Their uses as converbs often imparts a temporal meaning analogous to the spatial relation they add to nouns and pronouns. After conjugated verb forms ${ }^{1}$, these morphemes typically signal the subordination of one event to another:

(3) The locative morpheme used as a converb (clausal subordinator)
só̀̀y
dolin-ka
is-qú
aqtá-m
there they.lived-LOC fish-kill.INF good-N.PRED
'When they lived there the fishing was good.'

(4) The translative morpheme used as a converb (clausal subordinator)
qójataq-esay
$d a-q s^{?} t$
he.becomes.bear-TRANSL MASC.POSS-wish

'He wants to become a bear (His wish is that he becomes a bear).'

Other RMs require a connector morph agreeing in person, number, gender, and class with the preceding word. In the examples below, these connectors will be glossed $\mathrm{M}$ for masculine animate singular, $\mathrm{F}$ for feminine animate singular, PL for animate plural, and $\mathrm{N}$ for neuter, or inanimate class. The neuter connector appears after singular and plural inanimate-class nouns as well as after finite verbs. Etymologically, these connectors derive from the homonymous $3^{\text {rd }}$ person pronominal clitics used in possessive constructions (\$3.2.1), which likewise agree in person, number, gender, and class with the word form over which they have semantic scope. RMs requiring connectors will be called "augmented RMs". They include the remaining the "case suffixes" (5) as well as most "postpositions" (6):

(5) Use of the ablative formant yal as part of a nominal 'case suffix'

\footnotetext{
${ }^{1}$ Due to their complexity, finite verb forms are divided into constituent morphemes only when their internal structure is relevant to the discussion. All bound RMs are attached to their host by a hyphen. Except where noted, examples derive from my fieldwork in Tomsk in April-May 2005 with V. A. Romanenkova and M. M. Irikova, native speakers of Southern Ket. Note that/d/ is realized between vowels as the rhotic flap [r] in the dialect transcribed.
} 
hissej-di-yal $d s^{2} \eta \quad d \varepsilon^{2} \eta \quad$ dimesin
forest-N-ABL three men they.came
'Three men came from the forest.'

(6) Use of the morpheme ugde 'long' with a connector augment to mean 'during'

$\begin{array}{llll}\text { úl-es-da-ugde } & \grave{n} n & \text { bólba-n } & \text { síajtanıq } \\ \text { water-weather-M-long } & \text { many } & \text { mushroom-PL } & \text { they.appeared }\end{array}$

'Many mushrooms appeared during the rainy weather.' ( $\bar{e}$ 's 'sky, weather' is masculine class)

As stated earlier, the formal difference between augmented RMs (5-6) and simple RMs (1-4) does not parallel any semantic distinction one might draw to distinguish case affixes from postpositions. Both simple (7) and augmented RMs (8) may function as converbs (clausal subordinators) when attached to conjugated verb forms:

(7) Use of the ablative morpheme yal as part of a converb construction

$\begin{array}{llllll}\text { át-na } & q \bar{\imath} ’ p & \text { dúno-di-yal } & \text { kisćy } & \text { qáddðq } & \text { sćl-am } \\ \text { we-ANIM.PL.POSS } & \text { grandfather } & \text { he.died-N-ABL } & \text { here } & \text { very } & \text { bad-N.PRED }\end{array}$

'Since our grandfather died it has been very bad here.'

(8) Use of ugde 'long' as part of a converb construction meaning 'while, as long as'

$\begin{array}{llll}\text { ulólta-d-ugde } & \bar{\partial} t & \text { tsésoltan } & \text { qús-ka } \\ \text { it.rained-N-long } & \text { we } & \text { we.sat } & \text { tent-LOC }\end{array}$

'While it was raining, we sat in the tent.'

The present paper argues that all simple as well as augmented RMs - irrespective of whether they attach to nominals or finite verbs and regardless of their degree of semantic specificity - represent a unified functional category. Section 2 describes some basic features of Ket prosodic phonology to demonstrate that only a few categories of bound morphemes - namely roots, derivational affixes and plural suffixes - form a single phonological word with their base. Section 3 discusses three prosodic subgroups of relational clitics: augmented RMs, simple RMs, and possessive pronominal morphs, which may appear as proclitics or enclitics. When prosodic information is considered, all postposed RMs turn out to be enclitics rather than suffixes. Section 4 demonstrates that the so-called case markers, postpositions, and converbs in fact serve the identical morphosyntactic function of negating the head status of their nominal or finite verb hosts by converting them into adjuncts. Since they neither encode grammatical relations nor are restricted to nominal forms, RMs differ significantly from the canonical case markers of languages like Russian or Latin, as Vall \& Kanakin (1990) first pointed out. Our conclusion reiterates the basic premise that RMs represent a general morphosyntactic category of head-negating enclitics rather than a system of inflections that build discrete paradigms of word forms belonging to a single part of speech.

\section{Prosody and the phonological status of bound morphemes in Ket}


This section offers a brief excursus into Ket lexical and prosodic phonology, needed to show that RMs are clitics rather than true affixes that integrate with their base to yield a unified phonological word. Their clitic status, in turn, helps explain why most of them attach so promiscuously to conjugated verbs as well as to nouns and pronouns, since they do not generate word forms of the lexemes they combine with. The combination of word form plus RM creates a morphosyntactic unit but not a phonological word. As a syntactic atom, RM modified words share more in common with free phrases than morphological words.

As argued in Vajda (2003, 2004), Ket monosyllabic phonological words are distinguished by a system of four phonemic suprasegmental contrasts. These prosodemes are not simple melodic tones, but rather are based on an amalgam of pitch, length, vowel quality, and phonation state. Table (9) shows the features that interact to build the four Ket prosodemes:

(9) Feature bundles that create Ket monosyllabic prosodemes

\begin{tabular}{|c|c|c|c|c|}
\hline & $\begin{array}{l}\text { tonal } \\
\text { melody }\end{array}$ & $\begin{array}{l}\text { vowel length } \\
\text { (syllable type) }\end{array}$ & $\begin{array}{l}\text { phonation } \\
\text { type }\end{array}$ & $\begin{array}{l}\text { mid-vowel } \\
\text { quality }\end{array}$ \\
\hline $\begin{array}{l}q \bar{o}^{\prime} j \\
\text { 'uncle, aunt' }\end{array}$ & high-even & $\begin{array}{l}\text { half-long } \\
\text { (closed or open) }\end{array}$ & neutral & tense $[\mathrm{e}, \gamma, \mathrm{o}]$ \\
\hline $\begin{array}{l}q \partial^{i} j \\
\text { 'wish' }\end{array}$ & abrupt rising & $\begin{array}{l}\text { short } \\
\text { (closed or open) }\end{array}$ & creaky & $\operatorname{lax}[\varepsilon, \Lambda, \supset]$ \\
\hline $\begin{array}{l}\text { qój̀j } \\
\text { 'neighboring' }\end{array}$ & rising-falling & $\begin{array}{l}\text { long } \\
\text { (closed or open) }\end{array}$ & neutral & $\operatorname{lax}[\varepsilon, \Lambda, \supset]$ \\
\hline $\begin{array}{l}\text { q’̀j } \\
\text { 'bear' }\end{array}$ & falling & $\begin{array}{l}\text { short } \\
\text { (closed only) }\end{array}$ & neutral & $\operatorname{lax}[\varepsilon, \Lambda$, ৩ $]$ \\
\hline
\end{tabular}

The four-way prosodic distinction shown in (9) is largely absent in longer phonological words. Prosody in disyllables, including root compounds, reduces to a rising pitch on the initial syllable and falling pitch on the second. In most cases, this pitch contour is identical to that of long-vowel monosyllables. For this reason Vajda (2003) marked both types using the symbol ' '.

(10) Words with rising-falling pitch
qúj̀j 'neighboring'
qúqpùn 'cuckoo'
qókì 'body armor'

A smaller number of disyllabic phonological words possess an inherent rising/high-falling melody, which Vajda (2003) marked using the symbol“" ".

(11) Words with rising-high falling pitch

$$
\text { qúqpün 'cuckoo' qúglöq 'bell' qóppès 'tent smoke hole' }
$$

In this prosodic type, the falling portion descends from a higher register than in the simple rising/falling contour. Minimal pairs between these two prosodic types of disyllables do occur (12) but are relatively uncommon since rising/high-falling pitch mainly occurs in disyllables originating from the elision of a segment in the second half of the word: 
(12) The etymology of rising/high-falling pitch in one disyllabic word

qúqpün 'cuckoos' < qúqpùn 'cuckoo' + $n$ 'plural suffix'

These disyllabic tonal contours pattern as allophonic variants of certain monosyllabic prosodemes, with which they sometimes stand in free variation due to optional elision of intervocalic gutturals in fast speech:

(13) Free variation between monosyllabic and disyllabic pitch contours

\begin{tabular}{|c|c|}
\hline slower speech & faster speech \\
\hline rising/falling pitch in a disyllable & $=$ rising $/$ falling pitch in a monosyllable \\
\hline kísùn 'fox' & kúîn 'fox' \\
\hline \multicolumn{2}{|c|}{ rising/high falling pitch in a disyllable $=$ high-even tone in a monosyllable } \\
\hline kísü̈n 'foxes' & $k \bar{\gamma} " n$ 'foxes' \\
\hline
\end{tabular}

Both monosyllabic and disyllabic phonological words tend to lose some or all of their inherent lexical prosody unless pronounced in isolation or under pragmatic focus. The disyllabic pitch contours are replaced by a non-melodic word accent on the peak syllable whenever the word is defocused.

(14) Prosodic variation in disyllables reflecting functional sentence perspective

\begin{tabular}{|ll|} 
pitch contour retained under focus & non-melodic accent when unfocused \\
\hline kর́sùn 'fox' & kর́sun 'fox' \\
\hline kর́sün 'foxes' & kısún 'foxes' \\
\hline
\end{tabular}

The next two sections examine the prosodic effects produced when morphemes are joined into lexical or syntactic units. Our analysis shows that proclitics never alter the prosodic phonology of their hosts, while enclitics do so to varying degrees depending on information structure in the sentence. Affixes obligatorily alter the prosody of their base.

To avoid defining the notion of clitic using semantic criteria alone, an independent formal test is needed to distinguish between the prosodic effects of enclitics as opposed to that of lexically integrated suffixes. One such test is available using the rightmost subject agreement marker found in many finite verbs. These markers form part of the morphological verb yet encliticize to any available word in the same breath group, including adverbs and particles with which they share no special functional relationship. Since these morphemes are obviously not lexical suffixes on the preceding word, they provide an unambigous test for measuring the prosodic effects of enclisis. Compare (15), where no enclisis occurs because the frequentative particle receives contextual emphasis, with (16), where the subject agreement morph has attached to the preceding particle:

(15) No enclisis of the subject agreement morph da on the preceding frequentative particle ba ${ }^{2} \mathrm{t}$ 


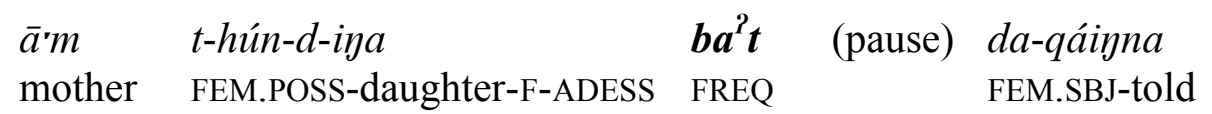

'Mother used to tell her daughter.'

(16) Enclisis of the subject agreement morph da on the preceding frequentative particle ba ${ }^{?} \mathrm{t}$

$\begin{array}{llll}\bar{a}^{\prime} m & \text { t-hún-d-ina } & \text { bá-ra } & \text { qáinna } \\ \text { mother } & \text { FEM.POSS-daughter-F-ADESS } & \text { FREQ-FEM.SBJ } & \text { told } \\ \text { 'Mother used to tell her daughter.' } & & \end{array}$

The next section will show that postposed RMs produce the same type of optional prosodic erosion in the preceding word depending on speech style and functional sentence perspective. They are therefore enclitics rather than lexically integrated affixes. All of the RMs traditionally regarded as cases, postpositions, or converbs turn out to be enclitics by this measure. Recognizing the difference between affix and clitic in Ket also helps elucidate the phonological status of the three mid-vowel pairs $[e, \varepsilon],[\gamma, \Lambda]$, and $[o, o]$, which are revealed as allophonic variants rather than phonemes when prosodic domains are fully taken into account.

\subsection{Lexically integrated vs. non-integrated bound morphemes}

Vajda (2006) showed that Ket possesses relatively few derivational affixes, with root compounding being the preferred morphological means of creating new lexical stems. The derivational affixes that do exist resemble bound roots in that, when combined with another root, they integrate prosodically to form a single phonological word. Consequently, disyllabic root compounds and derived stems have rising-falling prosody when pronounced in isolation or under focus. When defocused, their pitch tends to be replaced by a non-melodic accent on the first syllable. Some examples appear in (17) and (18):

(17) Example of prosodic leveling during root compounding

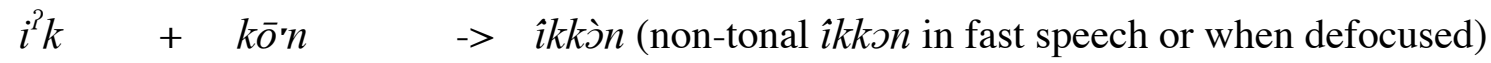

$$
\begin{aligned}
& \text { 'male' + 'horse' } \quad->\text { 'stallion' }
\end{aligned}
$$

(18) Example of prosodic leveling during suffixal derivation

$$
\begin{array}{lllll}
s \bar{u} l l & + & t u & -> & \text { súltù (non-tonal súltu in fast speech or when defocused) } \\
\text { 'blood' }+ & \text { 'adjective' } & -> & \text { 'bloody' }
\end{array}
$$

RMs do not obligatorily produce prosodic leveling in the forms to which they attach. Although they may trigger full prosodic leveling of their host (19a), at least some of the host's prosodic qualities tend to remain intact under contextual focus (19b):

(19) Examples of non-tonal prosody in nouns combined with grammatical morphemes

a. Pragmatically neutral pronunciation with full prosodic erosion

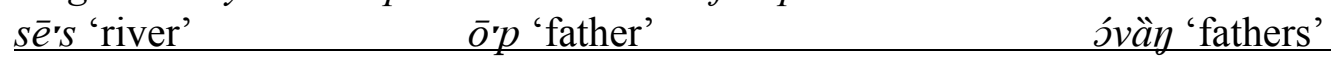


$s \varepsilon ́ s-k a$

river-LOC

'at the river' śb-da-ya

father-MASC.SG-DAT

'to the father' śvay-na-ya

fathers-ANIM.PL-DAT

'to the fathers'

b. Pronunciation under focus showing varying degrees of prosodic erosion

\begin{tabular}{|c|c|c|}
\hline$\underline{s e} \bar{e}^{\prime}$ 'river' & $\bar{o}^{\prime} p$ 'father' & óväy 'fathers' \\
\hline$s \bar{e} r s-k a(s \bar{e} s-k a, s e s-k a)$ & $\bar{o}^{\prime} b-d a-\eta a(\bar{o} b-d a-\eta a, o ́ b-d a-\eta a)$ & óvăy-na-ya (วváy-na-ya) \\
\hline river-LOC & father-MASC.SG-DAT & fathers-ANIM.PL-DAT \\
\hline 'at the river' & 'to father' & 'to the fathers' \\
\hline
\end{tabular}

This prosodic variability helps express information structure. Exactly the same pattern is evident in free phrases, where attributive adjectives show varying degrees of prosodic erosion in connection with contextual emphasis (20a,b):

\section{(20) Varying degrees of prosodic erosion in combinations of the roots $\mathrm{ki}^{?}{ }^{\prime} n e w^{\prime}+\mathrm{k \varepsilon}^{2} \mathrm{t}$ 'man'}

a. Neutral free phrase, with erosion of modifier prosody: $\quad k i k \varepsilon^{2} t$ 'new man'

b. Free phrase with contextual focus on the modifier: $k i^{2} k \varepsilon^{2} t$ 'new man'

c. Root compound, with erosion of prosody on both roots: kîyet 'young man'

This variability in prosodic reduction is not available to roots joined in lexical compounds (19c), whose internal constituents are no longer accessible to pragmatically conditioned rules.

Plural suffixes are likewise identifiable as lexically integrated affixes since they obligatorily trigger prosodic erosion in their base. Their phonological status differs from the bound grammatical morphemes we have identified as RMs, which level their host's prosody in degrees regulated by functional sentence perspective. Like roots and derivational affixes, plural suffixes form a single phonological word with the stems they attach to. When a plural suffix adds a syllable to a monosyllabic stem, it triggers a reduction in phonemic prosody that cannot vary by degree to express functional sentence perspective:

\section{(21) Prosodic changes in noun roots triggered by plural suffixation}

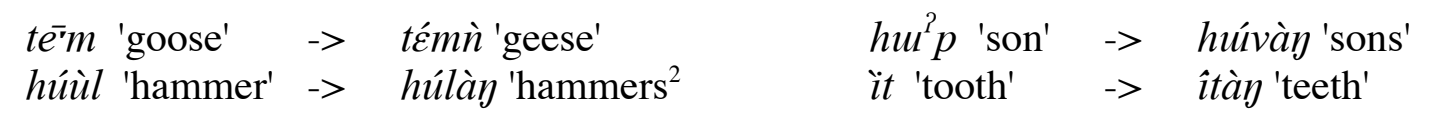

Prosodic leveling obligatorily occurs regardless of stylistic or pragmatic factors. Plural suffixes thus pattern with derivational affixes and bound roots as lexically integrated elements. Interestingly, these morphemes resemble derivational suffixes morphologically, as well, in having the ability to appear on nouns (22a) and adjectives (22b) incorporated into finite verb forms:

\section{(22) Plural morphemes added to incorporates in finite verbs}

\footnotetext{
${ }^{2}$ Roots containing two full vowel moras constitute a partial exception, as vowel length may remain in some lexical items: súùl 'snowsled' -> sóùlay 'snowsleds'. The reduction of long vowels during word formation appears to be morphophonological and dependent on etymological rather than on synchronic phonological factors. This also suggests that long-vowel nuclei are the prosodic equivalent of disyllables, an observation that concurs with the risingfalling stress in long-vowel monosyllables as well as disyllables.
} 
a. Finite verb forms with singular vs. plural noun incorporates

\begin{tabular}{|c|c|}
\hline $\begin{array}{l}\text { daínlivet } \\
\text { da-in-l-bet }\end{array}$ & $\begin{array}{l}\text { daínaylivet } \\
\text { da-in-ay-l-bet }\end{array}$ \\
\hline 3FEM.SBJ-needle-PAST-make & 3FEM.SBJ-needle-PL -PAST-make \\
\hline 'she made a needle' & 'she made needles' \\
\hline \multicolumn{2}{|c|}{ Finite verb forms with singular vs. plural adjectival incorporates } \\
\hline tqátapsin & tqántapsin \\
\hline$-q a-t-a j-\sin$ & $d i-q a-y-t-a \eta-s i n$ \\
\hline BJ-big-cause-3M.OBJ-become & 1 SBJ-big-PL-cause-3 ANIM.PL.OBJ-become \\
\hline make him bigger' & 'I make them (animate-class) bigger' \\
\hline
\end{tabular}

By contrast, relational enclitics cannot be added to incorporates ${ }^{3}$.

The next two sections further demonstrate that postposed RMs, unlike plural suffixes, are not part of the same word form as their host prosodically or morphologically, though they form a syntactic unit with it.

\subsection{The prosodic patterning of relational morphemes in Ket}

Werner (1997) lists 12 cases for Ket. Prosodically, the morphemes involved can be divided into four groups. The first is the vocative, which represents a special type of intonation phrase requiring full leveling of the lexical prosody with a distinctive pitch rise on the final syllable:

(23) Example of a vocative form

dularój̀ 'Oh, children!' (< dúlgàt 'children')

No other word forms obligatorily stress the absolute final syllable, and vocatives can be considered a special type of intonation phrase. The second case-like suffix with exceptional prosodic characteristics is the possessive pronominal clitic that also serves as an augment for certain other RMs (§3.2.1). In its literal possessive function, this morpheme can occur as either a proclitic or enclitic, depending on context, just like the rightmost subject agreement markers discussed above. The two remaining groups of case-like morphemes are enclitics. Case-like markers and postpositions that require augmentation by the possessive clitic - the forms we have been calling augmented RMs - are regular clitics; i.e., they occur as full words under certain circumstances. Combinations of possessive augment plus relational morpheme are pronounced as independent phonological words whenever their host is dropped in discourse (§3.2.2). Simple RMs, which include case-like markers and postpositions not requiring a possessive augment, are obligatory enclitics and their hosts cannot be dropped in discourse (\$3.2.3). Since the vocative does not interact syntactically with other elements in the phrase or sentence, it is not a true RM and will not be considered further here.

\footnotetext{
${ }^{3}$ Possessive proclitics can, however, be added to intransitive verbs whose logical subject is expressed verb-internally by a possessive construction as incorporate: p-síverej-bata 'I whisper' (literally, 'my-whispering-resounds').
} 


\subsubsection{Possessive pronominal clitics}

Ket possessive pronouns agree in person, number, gender, and animacy with the possessor in the following way:

(24) Pronominal possessive clitics

\begin{tabular}{|l|c|}
\hline \multicolumn{1}{|c|}{ singular } & plural \\
\hline$b-1 \mathrm{p}$ & $n a-$ animate (includes 1p and 2p, as well as \\
$k-2 \mathrm{p}$ & all 3p masc. or fem.-class nominals) \\
$d a-3 \mathrm{p}$ masculine-class & $d i-$ inanimate (includes all neuter-class \\
$d i-3 \mathrm{p}$ feminine- or neuter-class & nominals, as well as finite verb forms) \\
\hline
\end{tabular}

These markers may be realized either as proclitics or enclitics, depending upon context. All other bound RMs in nominal morphology are invariably postposed. The positional variability of possessive morphemes is illustrated in (25) using $3^{\text {rd }}$-person $d a$ 'his' and $d$ 'her'. In the same breath group, possessive morphemes encliticize to the possessor nominal (25a) or any preceding word (25b), but must be realized as a proclitic whenever preceded by a pause (25c):

(25) Possessive pronominal clitics

a. enclitic on possessor b. enclitic on unrelated word $b \bar{u}$-ra (pause) súùl (available word)-da (pause) súùl 3p-MASC.POSS sled (available word)-MASC.POSS sled c. proclitic on possessum

$$
\begin{aligned}
& \text { (pause) da-súùl } \\
& \text { MASC.POSS-sled }
\end{aligned}
$$

$b \bar{u}-r$ (pause) súùl (available word)-d (pause) súùl (pause) $t$-súùl 3p-FEM.POSS sled (available word)-FEM.POSS sled

FEM.POSS-sled

Notice that whenever the possessive morpheme is realized as a proclitic, it has no effect on the prosody of its host (26a). When realized as an enclitic, it triggers varying degrees of prosodic leveling in the host (26b).

(26) Degrees of prosodic leveling in the host of possessive enclitics

a. less leveling under focus bú'y-na (pause) súùl they-ANIM.PL.POSS sled 'their sled' b. more leveling when pronounced without emphasis

búy-na (pause) súùl
they-ANIM.PL.POSS sled
'their sled' (or 'their sled')

Possessive morphemes that appear as enclitics thus induce exactly the same pragmatically conditioned prosodic leveling in their host as other RMs, but have no effect on host prosody if they appear as proclitics. The chart in (27) categorizes monosyllabic prosodic features according to their susceptibility to reduction by enclitic attachment.

(27) Variability in host prosody caused by enclisis 


\begin{tabular}{|ccc|}
\hline most likely to reduce & less likely to reduce \\
\hline laryngealization $>$ melody $>$ length $>$ mid-vowel tenseness \\
\hline
\end{tabular}

Example 28 illustrates this pattern using monosyllabic hosts representing the four types of phonemic prosody. The prosody is partly to completely reduced by enclisis (28a) but remains fully intact under proclisis $(28 b)$ :

(28) Contrast in prosodic effects of enclitics $(a)$ vs. proclitics $(b)$ :

a. súl-d (pause) غ̀tl súl-da (pause) hóràp súùl-d (pause) qóvèt súl-d (pause) kū'p

blood-N.POSS color salmon-MASC.POSS tail sled-N.POSS back hook-N.POSS tip

'the color of blood' 'the salmon's tail' 'the sled's back' 'the cradle hook's tip'

\begin{tabular}{|c|c|c|c|}
\hline $\begin{array}{l}d-s \bar{u} \cdot l \\
\text { 'her (or its) blood' }\end{array}$ & $\begin{array}{l}d-s u^{?} l \\
\text { 'her (its) salmon' }\end{array}$ & $\begin{array}{l}\text { d-súùl } \\
\text { 'her (its) sled' }\end{array}$ & $\begin{array}{l}d \text {-sùl } \\
\text { 'her (its) hook' }\end{array}$ \\
\hline$d a-s \bar{u} \cdot l$ & $d a-s u^{?} l$ & da-súùl & $d a-s u ̀ l ~$ \\
\hline 'his blood' & 'his salmon' & 'his sled' & 'his hook' \\
\hline$n a-s \bar{u} \cdot l$ & $n a-s u^{?} l$ & na-súùl & na-sùl \\
\hline 'our, your, their blood' & 'our, your, their salmon' & 'our, your, their sled' & 'our, your, their hook' \\
\hline
\end{tabular}

This demonstrates that a special type of clitic-host boundary separates the possessive morphemes from the following word form. Across this boundary, proclitics generate the only word-initial consonant clusters found anywhere in Ket:

(29) Examples of onset clusters created by possessive pronominal proclisis

$p-q \jmath^{?} j$ 'my wish' $\quad k$ - $h u^{2} n$ 'your daughter' d-láyàt 'her forearm' $\quad d$-búyàj 'its drumming'

The position 8 subject markers in finite verb forms are the only other type of bound morpheme in Ket capable of attaching to either the preceding or following word (ex. 14-15 above). As proclitics, they likewise create onset clusters (cf. the verb in ex. 2 above).

The morphemes we have been calling RMs differ from possessive clitics in two ways. First, they never appear as proclitics. Second, they encliticize only to the word over which they have scope and must form a syntactic unit with their host. Like all enclitics in Ket, they trigger varying degrees of prosodic erosion in their host to help express functional sentence perspective.

The next two sections argue that all other RMs besides the possessive morpheme are enclitics.

\subsubsection{Augmented enclitics}

As already shown, relational enclitics comprise two formal groups based on the presence or absence of a preceding connector morph. This formal distinction, however, has no semantic correlate, since both groups contain case-like as well as postposition-like morphemes, many of which can also be used as converbs. 
Case-like RMs that require augmentation by a possessive connector include the ablative, dative, benefactive, and adessive morphemes:

(30) Case-like RMs requiring a possessive pronominal augment

\begin{tabular}{|c|c|c|c|c|c|c|}
\hline class & \multicolumn{2}{|c|}{ masculine animate class } & \multicolumn{2}{|c|}{ feminine animate class } & \multicolumn{2}{|c|}{ inanimate class } \\
\hline & 'god' & 'gods' & 'daughter' & 'daughters' & 'tent' & 'tents' \\
\hline $\mathrm{ABL}$ & $\varepsilon_{s} s-d a-\eta a l$ & $\varepsilon s-a \eta-n a-\eta a l$ & hún-di-nal & 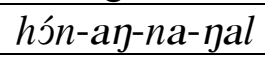 & qús-di-nal & qún-di-nal \\
\hline DAT & $\varepsilon^{\prime} s-d a-\eta a$ & $\varepsilon s-a \eta-n a-\eta a l$ & hún-di-na & 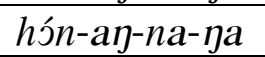 & 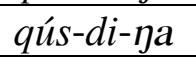 & qún-di-na \\
\hline $\mathrm{BEN}$ & $\varepsilon s-d a-t a$ & $\varepsilon s-a \eta-n$ & hún-di-ta & hón-ay-na-ta & $q u ́ s-d i-t a$ & $q u ́ \eta-d i-t a$ \\
\hline ADESS & $\varepsilon^{\prime} s-d a-\eta t a$ & $\varepsilon^{\prime} s-a \eta-n a-\eta t a$ & hún-di-nta & 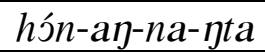 & qús-di-pta & $q u ́ \eta-d i-\eta t a$ \\
\hline
\end{tabular}

The majority of RMs listed as postpositions by Sherer (1983) and Werner (1997) are augmented. A few are monosyllabic and resemble the so-called Ket case suffixes in meaning, as well:

(31) Examples of monosyllabic augmented RMs traditionally regarded as postpositions

$\begin{array}{llll}\text { ígGus-t-qon } & \text { lám-d-nnt } & \text { kéd-da-tan } & \text { déy-na-tan } \\ \text { house-N-up.to } & \text { board-N-on } & \text { people-M-toward } & \text { people-ANIM.PL-toward } \\ \text { 'up to the house' } & \text { 'on the table' } & \text { 'toward the person' } & \text { 'toward the people' }\end{array}$

Most augmented RMs express more specific spatial meanings, however, and also formally consist of complexes of more than one relational morpheme:

(32) Examples of postposition-like augmented RMs consisting of several morphemes

déy-na-hut-ka

people-PL-under-LOC

'located under the people'
íyGus-n-d-kal-di-ya

house-PL-N-behind-N-DAT

'to the area behind the houses'
ígGus-n-d-inbal-di-yal house-PL-N-between-N-ABL 'out from between the houses'

All augmented RMs, including those traditionally regarded as case endings, may appear as independent words in contexts where the host is dropped to background it in discourse. This yields what appear to be floating case forms without a lexical base:

(33) An example of a "floating case form" in Ket

$\begin{array}{lll}\bar{a}^{\prime} m & \boldsymbol{d} \mathbf{i}-\boldsymbol{y} \boldsymbol{a} & \text { daqáiyna } \\ \text { mother } & \text { FEM.SING-DAT } & \text { she.told }\end{array}$

'Mother told her.'

The third-person animate singular anaphoric pronoun $b \bar{u} r$ is omitted in (32) because the referent is backgrounded in discourse, leaving only the class/number + dative combination diya to express the grammatical relation. The phonological-word status of such stranded RMs is evident from the stress on their initial syllable. In contexts where the referent is emphasized in context, the pronoun host $b \bar{u}^{\prime}$ would normally be retained, in which case the class/number + dative combination encliticizes to it and more closely resembles a case suffix: 
(34) Full pronominal form of the morphological dative

$\bar{a} ' m \quad$ bú-ri-ya daqáinna

mother 3-F-ABL she.told

'Mother told her.'

The ability of the ablative, dative, benefactive, and adessive morphemes to appear in the absence of any preceding noun or pronoun significantly distinguishes them from canonical case suffixes. Another problem with the view that these morphemes are case markers is that Ket has dozens of postpositions requiring basically the same system of class/number augments:

(35) Examples of postpositional constructions in Ket

$\begin{array}{lll}\text { súùl-d-áìt } & \text { óks-da-qon } & \text { déy-na-tan } \\ \text { sled-N-on } & \text { tree-M-up.to } & \text { people-PL-toward } \\ \text { 'on the sled' } & \text { 'toward the tree' } & \text { 'toward the people' }\end{array}$

Like the 'case' suffixes examined above, these and other postposition-like RM are capable of using their possessive augment as a base. They can therefore stand independently when the preceding noun or pronoun is dropped in discourse, demonstrating that they, too, belong to the class of regular clitics:

(36) Example of a postposition-like RM used without an accompanying nominal form

$\begin{array}{llll}\text { tu } & \text { qi'm } & \text { na-íl-ka } & \text { díyaraq } \\ \text { that } & \text { woman } & \text { ANIM.PL-near-LOC } & \text { she.lives }\end{array}$

'That woman lives near them.'

There is, however, a formal difference between the dative, ablative, adessive, and benefactive morphemes and other augmented RMs. The augmented relational morphemes traditionally identified as case markers cannot take word stress when they appear without a preceding host. The stress falls instead on the augment vowel:

(37) Examples of case-like augmented RMs stressed as prosodically independent words

$\begin{array}{llll}\text { ná-yal } & d a ́-\text {-yal } & \text { dí-yal } & \text { dí-yal } \\ \text { ANIM.PL.POSS-ABL } & \text { MASC.POSS-ABL } & \text { FEM.POSS-ABL } & \text { N.POSS-ABL } \\ \text { 'from them (anim.)' } & \text { 'from him' } & \text { 'from her' } & \text { 'from it, from them (inan.-class)' }\end{array}$

By contrast, postposition-like RMs attract the stress when no nominal host precedes them, so that their augment appears as a proclitic, exactly like the pronominal proclitic on a possessor noun:

(38) Examples of postposition-like augmented RMs stressed as prosodically independent words
$n a-i ́ l-k a$
da-húj-ka
d-kál-ka
$d-\hat{i}$ ìt-ka 
ANIM.PL.POSS-near-LOC

'near them (animate)'
MASC.POSS-in-LOC

'inside him'
FEM.POSS-behind-LOC

'behind her'
N.POSS-On-LOC

'on it, on them'

Note also that the feminine- or neuter-class augment in such combinations is non-syllabic $d$, rather than the syllabic allomorph $d i$ that appears before the dative, ablative, adessive, and benefactive morphemes:

(39) Examples of case-like augmented RMs stressed as prosodically independent words

\begin{tabular}{llll} 
dative & ablative & adessive & benefactive \\
\hline di-yal & di- $y$ ta & di- $y a$ & di-ta \\
FEM.POSS-ABL & FEM.POSS-ADESS & FEM.POSS-DAT & FEM.POSS-BEN \\
'from her' & 'by her' & 'to her' & 'for her'
\end{tabular}

This formal distinction roughly parallels the semantic difference between more case-like generic meanings (from, by, to, for) vs. more specific spatial meanings (beneath, near, above, between, toward, etc.). Also, the etymology of case-like RMs is completely opaque, while postpositionlike RMs are often etymologically connected with a nominal root:

(40) Examples of nouns (a) and homonymous postposition-like RMs (b)

a. Nouns: $h \bar{u} \bar{u}^{\prime} j$ 'stomach' র́sàt 'back' kī'p 'beak, tip' ínbàl 'space between objects'

b. RMs: - -hwj 'inside' - -nnt 'on' -kup 'between' -ínbal 'between'

The inability of certain RMs - namely the dative, adessive, ablative, and benefactive - to take stress even when they appear in the absence of the nominal over which they have semantic scope, coupled with their monosyllabicity and their opaque etymologies, could be viewed as a step in the development of a case system. However, this formal distinction has no analog among simple RMs, which comprise an equal number of the so-called case suffixes.

\subsubsection{Non-augmented enclitics}

The remaining four morphemes traditionally regarded as case markers must in all contexts directly follow the noun or pronoun over which they have semantic scope. They never combine with possessive augments and it is not possible to drop their nominal host in discourse. Because simple RMs never occur as phonological words separate from their host, they must be regarded as obligatory enclitics rather than regular clitics, unlike augmented RMs. The simple RMs traditionally regarded as case suffixes are the morphemes $k a$, used to denote general location with inanimate-class nouns, prosecutive bes denoting motion along or past, as denoting instrumentality or comitative meaning, and caritive an used to denote the absence of an item. Because these morphemes are added to the preceding word form without a possessive connector, they involve no distinctions in person, gender, number, or class.

\section{(41) 'Case' markers that lack a possessive pronominal connector augment}

\begin{tabular}{|l|l|l|l|}
\hline class & masculine animate & feminine animate & inanimate \\
\hline
\end{tabular}




\begin{tabular}{|c|c|c|c|c|c|c|}
\hline & 'god' & 'gods' & 'daughter' & 'daughters' & 'tent' & 'tents' \\
\hline LOC & - & - & - & - & $q u ́ s-k a$ & qún-ka \\
\hline PROS & $\varepsilon s-b \varepsilon s$ & $\varepsilon^{\prime} s-a \eta-b \varepsilon s$ & hún-bes & 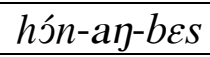 & $q u ́ s-b \varepsilon s$ & $q u ́ \eta-b \varepsilon s$ \\
\hline INSTR & $\dot{\varepsilon} s$-as & $\varepsilon_{s}-a \eta-a s$ & hún-as & hón-ay-as & $q u ́ s-a s$ & qún-as \\
\hline CAR & $\dot{\varepsilon} S-a n$ & $\dot{\varepsilon} s-a \eta-a n$ & hún-an & hón-ay-an & qús-an & qúp-an \\
\hline
\end{tabular}

Disyllabic relational morphemes that encliticize directly to nominals are traditionally regarded as particles or postpositions rather than case markers. One of these, the translative morpheme $\varepsilon s a \eta$, was introduced in $\$ 1$. This group also includes asqa, used in statements of comparison (qúj-asqa 'like a bear'), doyวt 'on account of, 'due to', and several others:

(42) The morpheme doyot 'on account of, 'due to' used after a noun

$\begin{array}{lcll}\text { bèj-dəyət } & \text { assáns } k \varepsilon^{2} t \quad \text { tónus } & \text { dbílibet } \\ \text { wind-because.of } & \text { hunt.INF man lean.to } & \text { he.made.it } \\ \text { 'The hunter made a lean-to because of the wind.' } & \end{array}$

Some RMs that do not begin with a possessive connector themselves may be followed by one of the so-called case endings - either augmented or simple - to create what could be called "complex RMs":

(43) Examples of complex RMs beginning with the simple relational enclitic bay 'time', 'place'

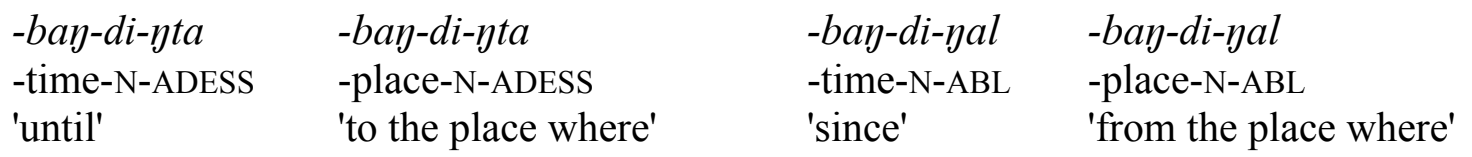

Complex enclitics of this sort always begin with a postposition-like RM - either simple (44a,b) or augmented $(44 c, d)$ - and end with a case-like RM, which may be simple (44a,c) or augmented $(44 b, d)$.

(44) The four possible combinations in morphologically complex RMs

a. simple postposition-like + simple case-like: $\quad k u p-k a \quad$ beak-LOC 'before, in front of'

b. simple postposition-like + augmented case-like: bay-di-yal place-N-ABL 'from where'

c. augmented postposition-like + simple case-like: $d$-ınt-ka N-back-LOC 'on top of'

d. augmented postposition-like +augm. case-like: d-hut-di-yal N-under-N-ABL 'from under'

The second possessive augment in such combinations is invariably the neuter form, since its underlying host is the immediately preceding RM. Case-like RMs never concatenate with one another in this way, nor are they ever followed by a non case-like RM. This formal patterning lends further credence to the notion that some RMs are nearer to case markers than others.

Prosodic evidence indicates that all RMs lacking a possessive connector - including complex ones ending in a case-like morpheme - actually represent a type of special clitic. Like suffixes, they obligatorily follow the form over which they have semantic scope. Unlike suffixes, however, they do not integrate lexically with their host to form a unified phonological word. In- 
stead, the host nominal may retain some or all of its underlying lexical prosody when foregrounded in discourse. The degree of prosodic erosion in such host-enclitic combinations is not conditioned by lexical phonology but rather by speech style and functional sentence perspective. As shown in $\S 3$, lexically integrated bound morphemes, including plural suffixes, trigger obligatory prosodic leveling in their base regardless of speech style or information structure, since the base itself, as part of the word form, is not independently accessible discourse-based prosodic rules.

\section{Relational enclitics as a general class of head-negating devices}

Identifying RMs as form-class changing enclitics rather than inflectional suffixes also helps explain why many of them - including most of the case-like morphemes among them - attach to finite verb forms as clausal subordinators. The copious examples in Werner (1997:349359) amply illustrate that case-like vs. non case-like RMs, augmented vs. non-augmented RMs, and non-complex vs. complex RMs - all may serve as converbs to convey a rich array of temporal (45) as well as non-temporal forms of subordination (46):

(45) Temporal subordination using kupka 'before' (literally, 'on the beak') (Werner 1997:351)
āt qáre ÉyĐu boyótn-kupka āt
qaséy $\quad k i^{?}$
$q u^{?} s$
thápts
I that village I.walk-before I there new house I.build.it
'Before I move to that village, I'll build a new house there.'

(46) Example of non-temporal subordination (Werner 1997:350)

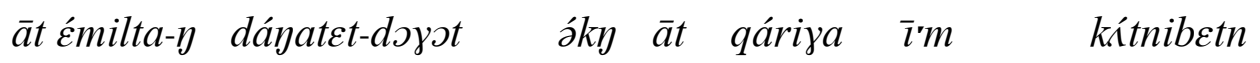

I cone-PL I.hit.them-since you I later pine.nuts you.give.them

'Since I am knocking down the cones, you give me the pine nuts later.'

The same RMs negate the head status of nominals, with the identical effect of converting them to adjuncts $(47,48)$ :

(47) Example of a pronoun turned into an adjunct using kupka 'before'

átn tkólin bún-na-kupka

we we.stood they-PL-before

'We stood before them.'

(48) Example of a noun converted to an adjunct using doyot 'for the sake of' (Werner 1997:312)

óp da-hwp-da-doyst bogdom tkájnam

father MASC.POSS-son-M-for gun he.took.it

'The father bought a gun for his son.' 
This list of examples could be expanded greatly, but it suffices to illustrate that the function unifying all of the semantically and formally diverse RMs is their ability to delete the morphologically inherent head status of the preceding nominal or finite verb.

Head-reducing enclitics are not required, however, to convert finite verb forms into attributive adjectival modifiers. Instead, inflected verbs become attributive modifiers simply by appearing immediately before a head noun:

(49) Three examples of inflected verb forms appearing as adjectival modifiers
só̀̀y dolín $d \varepsilon^{2} \eta$
úlaqan $\bar{l}$ 's
síbatan’q $i^{?}$
there they.lived people
it.boiled meat
I.was.born day
'the people who lived there'
'cooked meat'
'my birthday'

Noun stems, by contrast, generally require morphological marking in order to be converted into attributive modifiers ${ }^{4}$. Some add a possessive clitic (50), others an adjectival derivational suffix (51). The caritive morpheme also attaches to nouns to form modifiers meaning 'without' (52).

(50) Three examples of an inflected verb forms used as adjectival modifiers

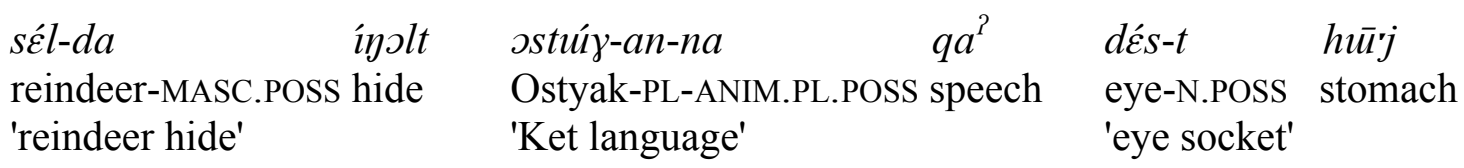

(51) Two examples of simple nominals used as attributive adjectives
súl-tu $\bar{l}$ 's
án-tu $\quad k \varepsilon^{2} t$
blood-ADJ meat
mind-ADJ man
'bloody meat'
'clever person'

(52) Noun +caritive morpheme an forming attributive modifiers denoting lack of the given item

$\begin{array}{llll}\text { sál-an } & d \jmath^{2} n & q a ́ \gamma-a n & k \varepsilon^{2} t \\ \text { sharp.edge-less } & \text { knife } & \text { speech-less } & \text { man } \\ \text { 'dull knife' } & & \text { 'silent person' } & \end{array}$

Because no other RMs are capable of building attributive modifiers and the morpheme an 'without' in such combinations triggers obligatory prosodic reduction of the root, it might be more appropriate to regard it as a derivational suffix analogous to English -less in speechless, bloodless, etc., rather than as an RM in this usage.

This morphological heterogeneity demonstrates that the syntactic class of modifiers (i.e., non-heads) in Ket is not as monolithic a category as Krjukova \& Grishina (2004) suggest. Rather, it contains various formal subdivisions, some of which correspond to traditional notions of adjective vs. adverb. This concurs with Dixon's (2004) argument that all languages possess a

\footnotetext{
${ }^{4}$ This does not include infinitive forms, which are inherent non-heads and therefore can be used as attributive modifiers (assáns $k \varepsilon^{2} t$ [hunt.INF person] 'hunter') without additional morphological marking.
} 
formal class of adjectives. However, the generic use of the nominalizing suffix $-s$ to create nouns out of adjectives (53a), possessive attributes (53b), as well as adjuncts created through headdeleting enclisis (53c) - suggests that the distinction between head and non-head in Ket syntax is nevertheless a fundamental one:

(53) Examples of an adjective (a), possessive (b), and adjunct (b) nominalized by the suffix -s

\begin{tabular}{ll}
\multicolumn{1}{c}{ non-head } & $>$ nominalized substantive \\
\hline a. súl-tu 'bloody' & $>$ súl-tu-s 'something (or someone) that is bloody' \\
b. ób- $d a$ 'father's' & $>$ ób- $d a-s$ 'something (or someone) belonging to father' \\
c. $t u ́ s-t-h u t-k a$ 'under a rock' & $>$ tús-t-hut-ka-s 'something (or someone) under a rock'
\end{tabular}

All of these facts taken together demonstrate that the morphological marking of head status in Ket interacts closely with word order patterns. Ket appears to be a language that strongly favors using the rightmost position to signal headedness in any rigidly ordered combination of elements. This generalization explains why attributes precede their head noun, and objects precede their verb. It also explains why a nominalizing suffix is needed to convert adjectives and adjuncts to substantives, but finite verbs become attributive modifiers without morphological modification, since they obligatorily precede their head and therefore do not violate the headedness-final rule. The only major exception is that nominals require morphological marking to convert to attributes, even though attributes are obligatorily followed by their head noun. Perhaps this is because two bare nominals in succession normally convey syntactic arguments in a verb phrase. Adjuncts are the only type of modifier with relative freedom of movement to precede or follow their head. Therefore, those created from nominals or finite verbs (head classes) nearly always require a head-reducing enclitic ${ }^{5}$. RMs therefore function to mark unambiguously the non-head status of derived adjuncts irrespective of the position they occupy in the sentence with respect to their syntactic head. Identifying RMs as a general class of headreducing enclitics also explains why they attach to nominals and finite verbs, but not to morphological adjectives and adverbs, with are inherently non-heads and therefore require no such identification. The set of enclitics used to "de-head" nominals and finite verbs encompasses all of the morphemes traditionally regarded as case markers, postpositions, or converbs. These seemingly disparate functional groups actually constitute a single morphosyntactic category. Perhaps their basic unity as head-reducing enclitics accounts for the perennial difficulty Ketologists have experienced in trying to divide them into discrete classes based on formal or functional criteria.

\section{Summary and conclusion}

Our analysis of bound grammatical morphemes in Ket supports the conclusion of Frans Plank (2002) that the concept of "case system" should involves a variety of features and cannot be defined in absolute terms. Although certain RMs display case-like semantic or formal properties, they represent nothing more than an ill-defined subset within a much larger functional category: the set of enclitics used to create adjuncts by "de-heading" nominals and verb forms. Simply stating that Ket possesses a case system (Werner 1997; Vajda 2004) or lacks a case system

\footnotetext{
${ }^{5}$ A rare exception is temporal nouns such as $b \bar{\imath} ' s$ 'evening' and qónj̀ks 'morning', which may function as durational adverbs without morphological modification of any kind.
} 
(Vall \& Kanakin 1990) fails to capture the true functional and typological status of these morphemes.

The fact that case-like morphemes in Ket do not comprise a functionally discrete group helps explain why they are formally diverse, as well. Ket contains two formally distinct types of relational enclitics - simple and augmented. Membership in each set appears to lack synchronic motivation, though the difference does serve a function in information structure. Simple enclitics must follow their host in all contexts and cannot stand as independent phonological words. Augmented enclitics are capable of forming a free-standing phonological word together with their possessive augment, thus allowing the host to drop when backgrounded in discourse. Among the morphemes traditionally regarded as case suffixes, the set of formally simple RMs include the locative, instrumental, prosecutive, and caritive, as well as several others traditionally labeled postpositions or particles. Augmented RMs include most of the postposition-like morphemes, as well as the dative, ablative, adessive, and benefactive. Which meanings receive expression through simple as opposed to augmented enclitics is due to etymological factors that merit additional investigation.

Head-reducing enclitics in Ket show a different type of prosodic patterning than lexically integrated morphemes. When encliticized to their host - be it a noun, pronoun, or finite verb RMs allow some of the host's inherent prosody to remain for purposes of expressing functional sentence perspective. By contrast, roots, derivational affixes and plural suffixes trigger obligatory prosodic reduction whenever they yield polysyllabic outputs. Enclitic-marked adjuncts therefore represent syntactic units rather than phonological words. Ket also contains a possessive pronominal marker, traditionally referred to as the genitive case when it encliticizes to a possessor nominal. This morpheme is distinctive in being able to appear as either proclitic or enclitic. As an enclitic, it need not attach to the word form over which it has semantic scope. Prosodically, it patterns most closely with pronominal clitics in finite verb morphology than with other RMs.

The function of head-reducing enclitics in Ket far exceeds the typical role of inflectional case markers. In terms of their capacity to generate syntactic units through morphological modification, head-negating enclitics differ significantly from inflections. Canonical case markers generate word forms without changing form class. Head-negating enclitics in Ket convert multiple form classes (nouns, pronouns, finite verbs) to a single syntactic class (adjuncts). This lends support to the position of Krjukova \& Grishina (2004) and Krjukova (2005) that Ket syntax is founded on a primary division between nominal, finite verb, and modifier - in other words, between noun-phrase head, verb-phrase head, and non-head. Enclitic-bearing adjuncts simply represent the set of modifiers created from word forms that might otherwise be misinterpreted as morphological heads.

\section{Abbreviations}

ABL - ablative, ADESS - adessive, ADJ - adjective-deriving suffix, ANIM - animate, BEN - benefactive, CAR - caritive, F or FEM - feminine, FREQ - frequentative particle, INF - infinitive, INSTR - instrumental, LOC - locative, M or MASC - masculine, N - neuter, PL - plural, PRED - predicative, PRES - present tense, PROS - prosecutive, TRANSL - translative, SING - singular

\section{References}


Castren, M. A. 1858. Versuch einer jenissej-ostjakischen und kottischen Sprachlehre. SanktPeterburg.

Dixon, R. M. W. 2004. Adjective classes. Oxford: Oxford University Press.

Dul'zon, A. P. 1968. Ketskij jazyk. Tomsk: Tomsk State University.

Krjukova, E. A. \& N. M. Grishina. 2004. "Novyj podkhod k probleme klassifikatsii chastej rechi v ketskom jazyke: klass slov opredelitelej". Sravnitel'no-istoricheskie i tipologicheskie issledovanija jazyka i kul'tury: problemy i perspektivy, 2. Tomsk: Tomsk Pedinstitute. Pp. 33-46.

Krjukova, E. A. 2005. Klass slov-opredelitelej v enisejskikh jazykakh. Aftoreferat Kandidatskoj dissertatsii. Tomsk.

Plank, Frans (ed.). 2002. Noun phrase structure in the languages of Europe. Berlin: Mouton.

Sherer, V. È. 1983. Poslelozhnye konstruktsii v ketskom jazyke. Aftoreferat Kandidatskoj dissertatsii. Leningrad.

Vall, M. \& I. Kanakin. 1990. Ocherk fonologii i grammatiki ketskogo jazyka. Novosibirsk: Nauka.

Vajda, Edward J. 2003. "Tone and Phoneme in Ket". Current trends in Caucasian, East European and Inner Asian linguistics: Papers in Honor of Howard I. Aronson, ed. Dee Ann Holisky \& Kevin Tuite. Amsterdam \& Philadelphia: John Benjamins.

Vajda, Edward J. 2004. Ket (Languages of the World/Materials, 204.) Munich: Lincom Europa.

Vajda, Edward J. 2006. "Ket morphology". Morphologies of Asia and Africa (including the Caucasus), ed. Alan Kaye. Winona Lake, IN: Eisenbrauns.

Werner, Heinrich. 1997. Die ketische Sprache. Wiesbaden: Harrasowitz. 